\title{
3D DIGITISATION IN CULTURAL HERITAGE KNOWLEDGE AND PRESERVATION: THE CASE OF THE NEPTUNE STATUE IN BOLOGNA AND ITS ARCHETYPE
}

\author{
V. A. Girelli ${ }^{1}$ *, M. A. Tini ${ }^{1}$, M. G. D’Apuzzo², G. Bitelli ${ }^{1}$ \\ ${ }^{1}$ Department of Civil, Chemical, Environmental and Materials Engineering (DICAM), University of Bologna, Viale del \\ Risorgimento 2, 40136 Bologna, Italy - (valentina.girelli, mariaalessandra.tini, gabriele.bitelli) @unibo.it \\ ${ }^{2}$ Istituzione Bologna Musei, Via Manzoni 4, 40121 Bologna, Italy - markgregory.dapuzzo@comune.bologna.it
}

\author{
Commission II, WG II/8
}

KEY WORDS: 3D digitisation, 3D modelling, Archetype, Cultural Heritage, 3D scanning, Structure from Motion

\begin{abstract}
:
In the field of Cultural Heritage, the availability of a complete, detailed and photo-realistic 3D model of the objects of interest permits to describe all the aspects related to geometry, colours and materials, as well as the work techniques and the decay state. Besides, it offers multiple possibilities for the documentation, the analysis and the study.

This paper describes the experience, carried out by the DICAM Geomatics group of the University of Bologna, about the 3D digitisation of two important statues of Neptune, by means of the integration of 3D image-based and range-based techniques. The two artworks, both realized by the sculptor Giambologna, are the big bronze statue of the god adorning the homonymous fountain, one of the most symbolic monuments of the city of Bologna, and its archetype, exhibited in one of the civic museums.

The obtained 3D models, beyond the important function of documentation, knowledge and preservation of the two objects, also permit a comparison between the small archetype, conveniently scaled, and the big final statue. In the manuscript all the surveying and data processing operations concerning the objects digitisation are described. Particular attention is paid to the problems related to the scale of the archetype and the comparison between the two obtained 3D models, with the aim to evaluate and represent the occurred changes.
\end{abstract}

\section{INTRODUCTION}

Digitisation is nowadays the first step in all the processes aimed to the documentation and conservation of cultural heritage (Bitelli et al., 2019).

According to the Merriam-Webster American dictionary, the first known use of the word digitisation was in 1954, in a meaning defined as "the process of converting something to digital form". Books, photographs, archaeological finds, artworks, sculptures and buildings can be today digitized, and all the information related to these objects, as for example geometric dimensions, shape, materials, colours and decay, can be processed, managed, stored and transmitted (Pieraccini et al., 2001).

Together with the digitisation, the other two fundamental elements in building digital cultural heritage could be identified with the preservation and the sharing. The availability of a virtual digital model of the object ensures the long-term memory of its current state, permitting the decay analysis, the planning of the conservative restoration, until the possibility to generate replicas (Balletti et al., 2017). Lastly, the digital model can guarantee the access to the object for experts and nonexperts, favouring on one side its knowledge and study and, on the other, its popularization by means of the creation of public databases available on the web or virtual museums (Bruno et al., 2010, Minto \& Remondino, 2014).

In this context, Geomatics contribution is crucial, offering different methods and tools dedicated to the 3D digitisation of objects (Bitelli et al., 2007). Techniques like photogrammetry and laser scanning are able to generate realistic $3 \mathrm{D}$ models, which combine high geometric accuracy and radiometric fidelity, and which can be used for different uses: from the basic digital recording and documentation to specific studies about material characteristics and decay; from high precision monitoring to structural analysis; from touristic exploitation to the $3 \mathrm{D}$ printing products.

Within the very wide area of cultural heritage, especially in the museum environment, there has been in recent years an increasingly widespread diffusion of 3D acquisition and modelling technologies. Many institutions recognize the importance of these modern technologies, for their ability to enrich with their final products the classic exhibitions, attracting an ever-wider audience of visitors and experts (Hollinger et al., 2013). Besides, a 3D model can be moved, explored, zoomed, scaled, sectioned, enlightened, emphasized and replicated, permitting to add new levels of viewing, reading and studying to those offered by the real object (Francolini et al., 2018).

In this framework, new and not always exploited possibilities are related to the objective comparison between a prototype, or archetype, of an object and its final realization; the problem is of high interest in the case of paintings or sculptures, till to complex architectures (Scopigno et al., 2011).

The paper describes an experience, carried out by the DICAM Geomatics group of the University of Bologna, about the integration of 3D structured-light projection scanning and Structure from Motion (SfM) techniques for the 3D digitisation of two bronze statues of the god Neptune. The first is the big statue adorning the homonymous fountain, one of the most symbolic monuments of the city of Bologna; the other is its archetype, a smaller statuette also in bronze, exhibited at the Medieval Civic Museum of the city.

The 3D modelling of the fountain constituted the first step of

* Corresponding author 
the most recent restoration of the monument, which took place in 2016. The 3D model of the statuette of Neptune, obtained integrating the geomatic techniques of digital photogrammetry and high-detail 3D scanning, beyond the important function of documentation, knowledge and preservation of the artwork, also has permitted - after a convenient scaling of the archetype model - a comparison between the two statues, with the aim to estimate and characterize the occurred changes.

After a brief description of the two statues, the main operations of surveying and data processing are described in the paper, with considerations about the faced problems and the adopted procedures and solutions.

\section{THE CASE STUDY}

The fountain of Neptune, located in the historic centre of Bologna, is one of the most iconic monuments of the city (Figure 1). Defined as one of the most remarkable examples of Renaissance fountain, it was designed and realized between 1563 and 1567, thanks to the collaboration of the Sicilian architect and painter Tomaso Laureti and the Flemish sculptor Jean de Boulogne of Douai, called Giambologna (Tuttle, 2015). On the top of the fountain stands massive the bronze statue of the god Neptune (height $3.2 \mathrm{~m}$ ), called "the Giant" for its imposing size (Figure 2).

The alleged archetype of the statue is preserved in the Civic Medieval Museum of Bologna and belongs to the important bronze collection of the museum (D'Apuzzo, 2017).

The statuette was found in Vienna by Count Luigi Ferdinando Marsili and returned to the city of Bologna in the early 1700s (Figure 3).

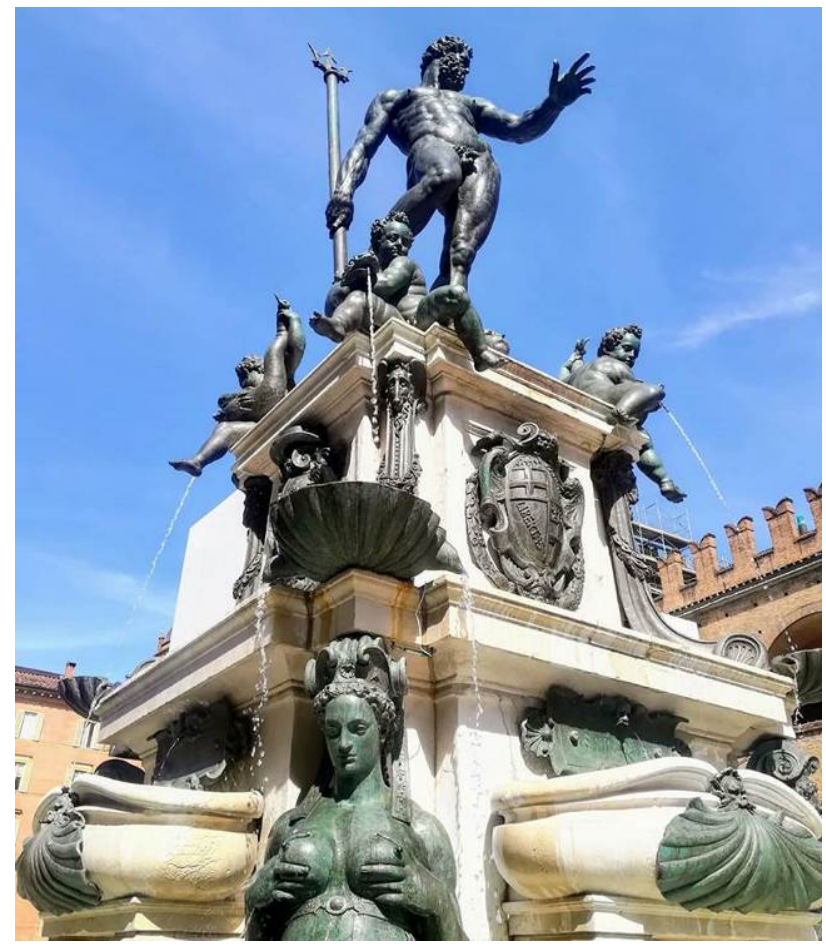

Figure 1. The bronze sculptural groups adorning the Fountain of Neptune in Bologna.

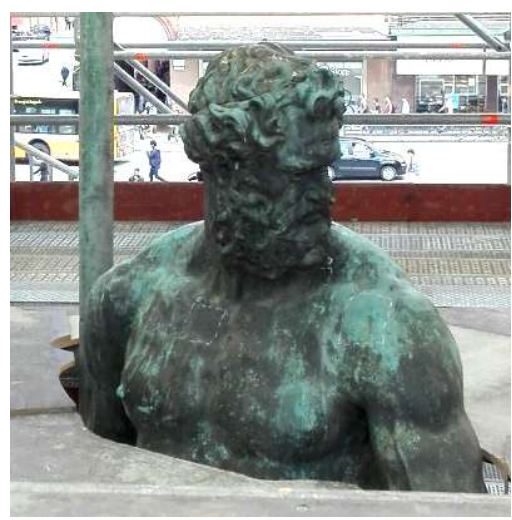

Figure 2. Neptune statue during the restoration works (detail).

The little Neptune (height $75 \mathrm{~cm}$ ) can be considered a kind of "test" of what the statue on the fountain would have looked like, a scaled model that the sculptor Giambologna wanted to submit in the year 1563 to Pope Pio IV for approval. The great final bronze was produced over the three subsequent years.

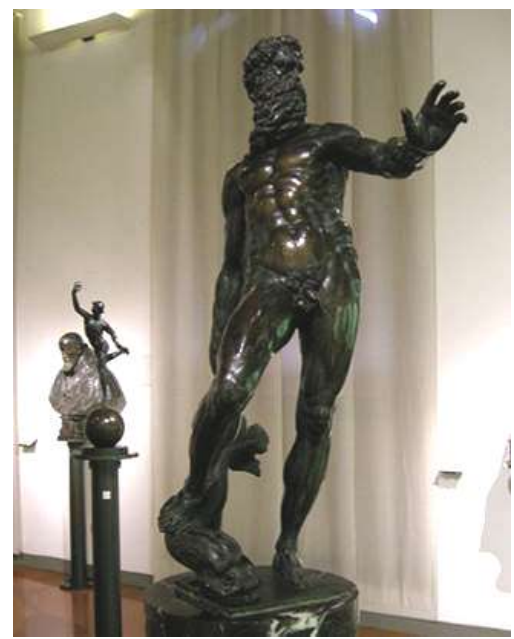

Figure 3. The archetype of the statue of Neptune, exhibited at the Civic Medieval Museum of Bologna.

\section{SURVEYING ACTIVITIES AND DATA PROCESSING}

\subsection{D acquisition and modelling of the Fountain of Neptune}

The restoration project of the Fountain of Neptune occurred in 2016-2017. It was an innovative project seeing involved the Municipality, the University of Bologna in a multidisciplinary team, the Visual Computing Lab of the CNR - ISTI (Pisa), the Istituto Superiore per la Conservazione e il Restauro - ISCR (Rome), the newspaper "Il Resto del Carlino" and the citizenship itself, involved in fundraising to partly finance the restoration. The project led to the creation of an innovative information system based on a very detailed $3 \mathrm{D}$ model to support and document all the works carried out during the restoration phase and future management activities.

Within the project, the DICAM Geomatics group has worked, in the context of the documentation and diagnostic phase, to realize the 3D model of the Fountain. 
Because of the object complexity and the need for products at different scales of detail, the surveying activities required the use of different techniques in a strict integration: traditional 3D terrestrial topography by Total Station for the object georeferencing; time-of-flight laser scanning for acquiring a general point cloud of the monument and the neighbouring context (Figures 4 and 5); high resolution 3D scanning (light structured projection) and digital photogrammetry for generating a very detailed photo-textured $3 \mathrm{D}$ model of the whole monument. The main surveying and data processing operations are described in detail in (Girelli et al., 2019).

A first overall $3 \mathrm{D}$ point cloud of the entire fountain, complete with the underground, required 27 scans measured by the laser scanner Riegl VZ400 (declared precision $3 \mathrm{~mm}$ ). Particularly difficult was the surveying of the subterranean tunnels, characterized by reduced spaces.

The alignment of the scans in a univocal and rigorous threedimensional reference system and the subsequent insertion of the acquired data in the large-scale technical cartography of the city, was realized thanks to a high-precision Total Station survey of many cylindrical and double-sided retro-reflecting targets, placed in the area.

After an accurate work of manual cleaning of the clouds from the numerous noise points corresponding to useless elements (people, pigeons, electrical and hydraulic tubes, etc.), the complete 3D point cloud of the fountain contains about 140 million points, filtered with an average spacing of $5 \mathrm{~mm}$ (Figure 4). This model served as a base for assembling the very large amount of datasets coming from subsequent very high resolution surveys.
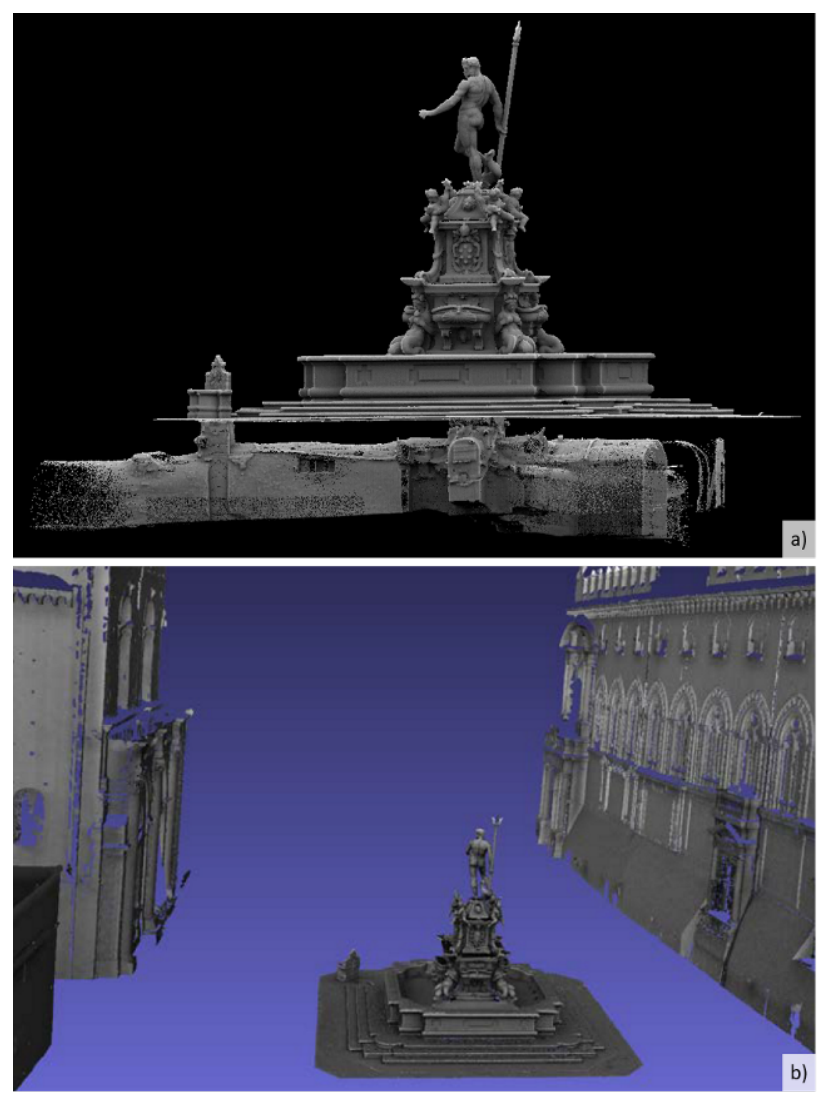

Figure 4. Point cloud of the Fountain of the Neptune (above and under-ground), obtained by the terrestrial laser scanning (a); the

$3 \mathrm{D}$ model (low resolution) and surrounding buildings (b).
The 3D model of the statues of Neptune was realized by meshing of the final point cloud.

In this case, in order to obtain a model as detailed as possible, the final cloud was filtered with a point spacing of about $1 \mathrm{~mm}$, feasible operation thanks to the high redundancy present on the statue surface considering the high number of measured clouds. The obtained 3D model, shown in Figure 5, consists in about 2.2 million of triangles. Since the scans were made from the ground, the model has some small gaps in different parts.

This model of the bronze statue has been adopted for a comparison with its archetype, with the aim to analyse the changes introduced by Giambologna in the final masterpiece.

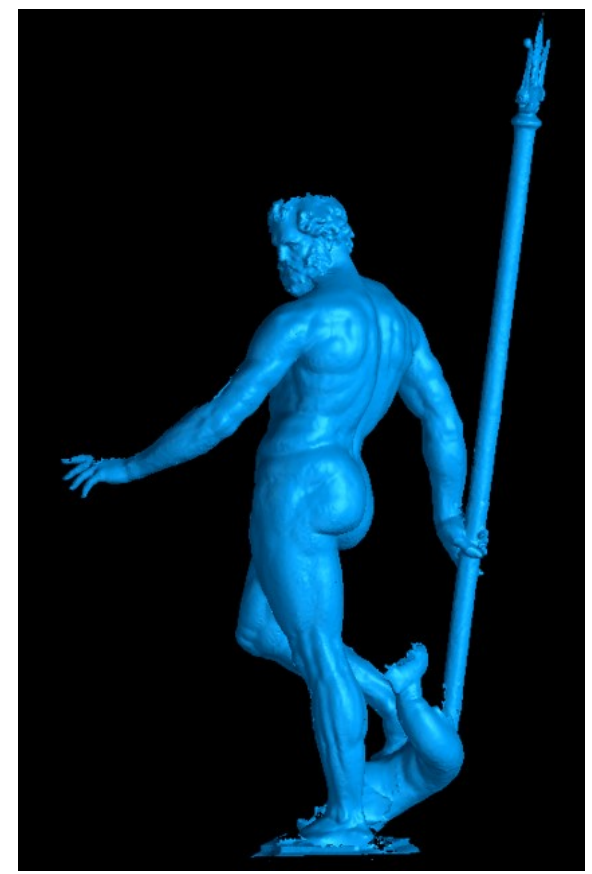

Figure 5. 3D model of the statue of Neptune.

\subsection{The 3D modelling of the archetype of the statue of Neptune}

The 3D digitisation of the archetype constituted a practical challenge, as regards both the surveying and the data processing. Structured-light projection scanner and automatic digital photogrammetry were utilized for generating the highresolution textured 3D model of the object. The integration between the two techniques was necessary to solve some problems related to the characteristics of the object (in geometry and material) and the logistic constraints caused by its location. The complex shape, rich of details and hidden areas, required a great number of scans (53); the chosen instrument was the Artec MHT structured-light 3D scanner, characterized by a nominal precision of $0.1 \mathrm{~mm}$.

The shiny texture and the dark colour typical of the bronze, combined with the artificial lights of the museum, produced however multiple reflections and consequent noise in the generated surfaces, gaps in the mesh and inhomogeneities in the texture, evidencing in this case some limitations of 3D scanning technique (Figure 6).

The acquisition of some protruding parts impossible to acquire by scanning techniques, as for example the Neptune's left hand, required the use of photogrammetry in order to obtain the complete 3D model of the object. About 40 images of the hand were acquired and processed following the SfM approach. The 
obtained model was scaled based on one distance taken at the wrist on the scanning model, then aligned with this one using ICP (Iterative Closest Point) method and finally merged (Figure 7).
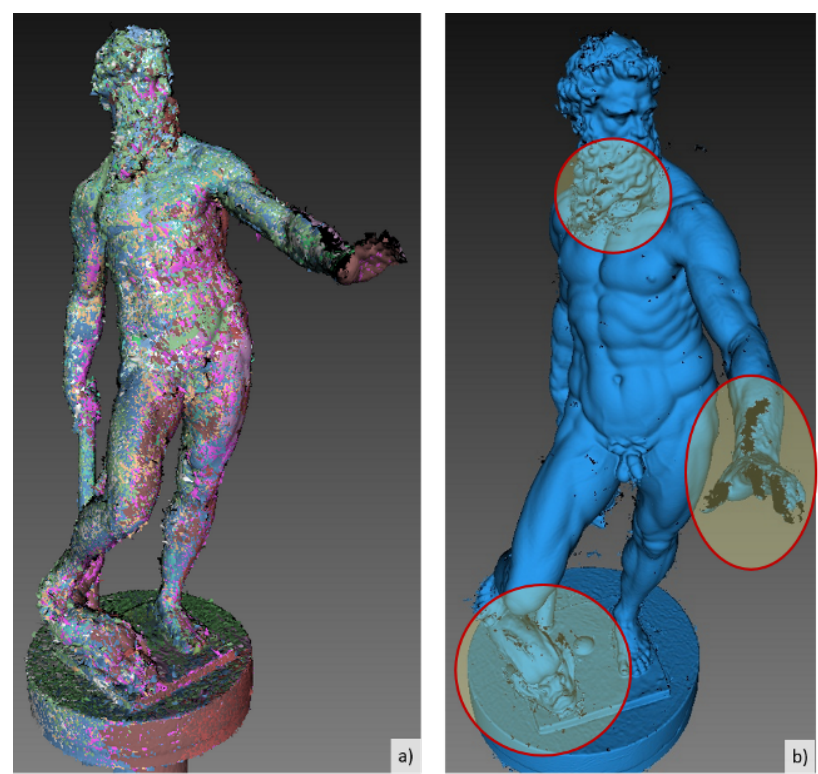

Figure 6. 3D modelling of the archetype by 3D scanning. (a) the 53 scans necessary for a complete acquisition; (b) the 3D model, with evidenced some problems as holes and noise.
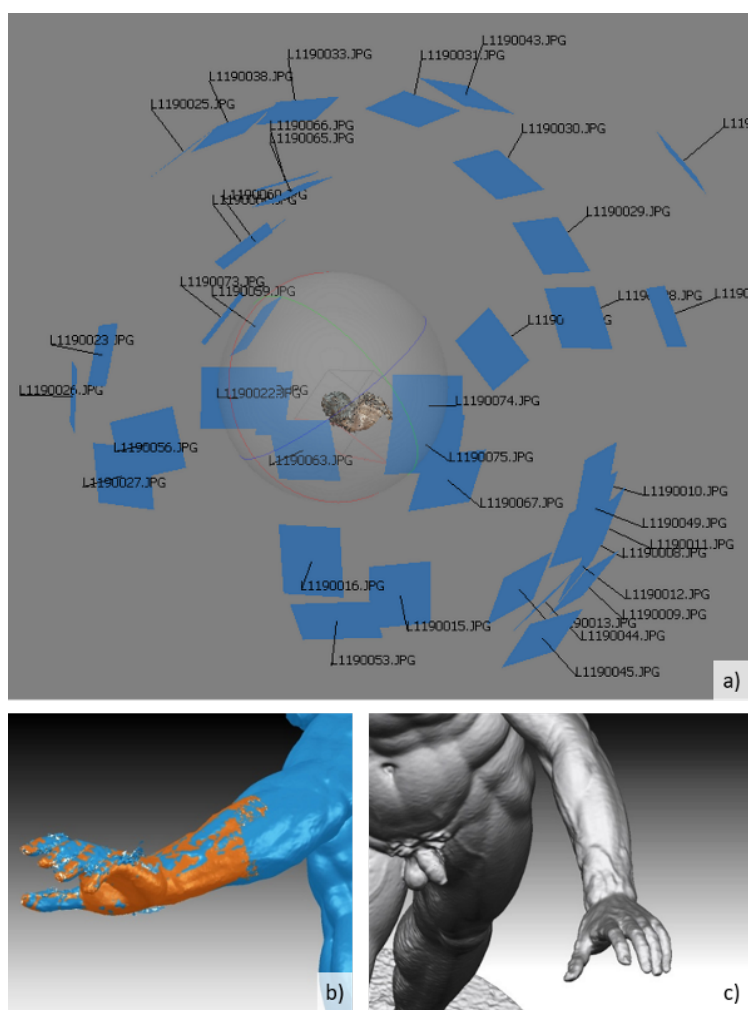

Figure 7. 3D modelling of the left hand by SfM (a); alignment between the model by SfM, in orange and the one by scanning, in blue (b); the two merged models (c).
At the end, a significant manual intervention by the operator was necessary to process all the data and to assist the software used for the mesh editing in many automatic tools, as for the example the holes filling and the noise and outliers removal.

The generated 3D model presents a very high degree of detail (about 3 million of points and 5.5 million of triangles, with a medium side of $0.5 \mathrm{~mm}$ ) and permits a very good exploration of the artwork, even higher than that obtainable from the direct visual exploration (Figures 8).
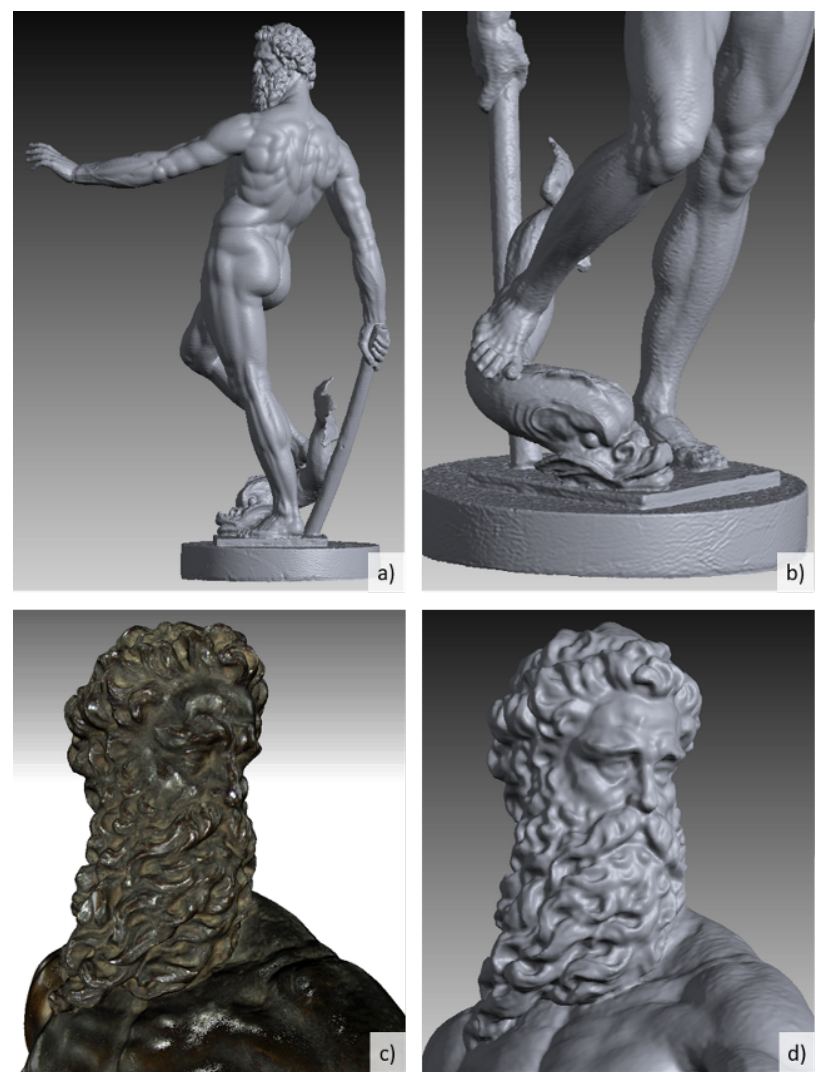

Figure 8 . The final 3D model of the archetype of the statue of Neptune (a), with some details: the base of the statuette (b); the head, in photo-textured (c) and shaded view (d).

\section{THE COMPARISON BETWEEN THE TWO ARTWORKS: PROBLEMS, SOLUTIONS AND CHANGES EVALUATION}

Considering that the little Neptune is the archetype of the big Neptune, a geometrical comparison between the two statues was experimented, with the aim to evaluate and describe the occurred changes in the realization of the two objects.

Already from a first visual analysis, the two artworks are actually very different in shape and proportions. For this reason, a quantitative comparison could be very difficult, even if the scaling and alignment of the archetype on the big statue model permits to underline some aspects taken into consideration by the sculptor in the realization of the final work.

Essentially the problems to face up were the scaling of the little Neptune and the definition of some common points to align the two statues.

The first tested strategy considers the length of the leg from the knee to the ankle as dimension through which determine the scale factor; the knees and the left feet were taken as common points to perform the alignment. 
The figure 9 shows the obtained comparison and permits to make some considerations.

The legs of the two statues have the same proportion, while the chest and the shoulders are much larger and stout in the big Neptune, probably for increase the solemnity of the figure.

In addition, the posture of the body, going backwards in particular in the right part of the model, is highlighted, almost wanting to show the will of the Neptune to get off the pedestal.
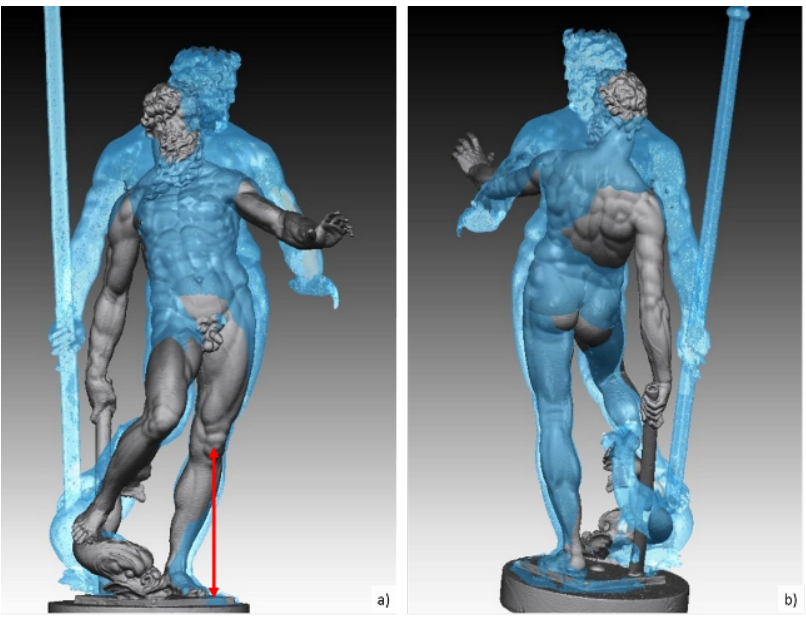

Figure 9. Two views of the comparison between the statues, after scaling the archetype using the length of the leg, evidenced in red (the light-blue model is the big Neptune, the grey model is the archetype).

The second comparison was made taking into consideration the global height of the statues, between the top of the hair and the ankle, making coincide the base for the alignment.

Also this comparison, shown in Figure 10, highlights the different posture of the big statue compared to its archetype, and the different proportions of the left arm, too long and high in the little Neptune.
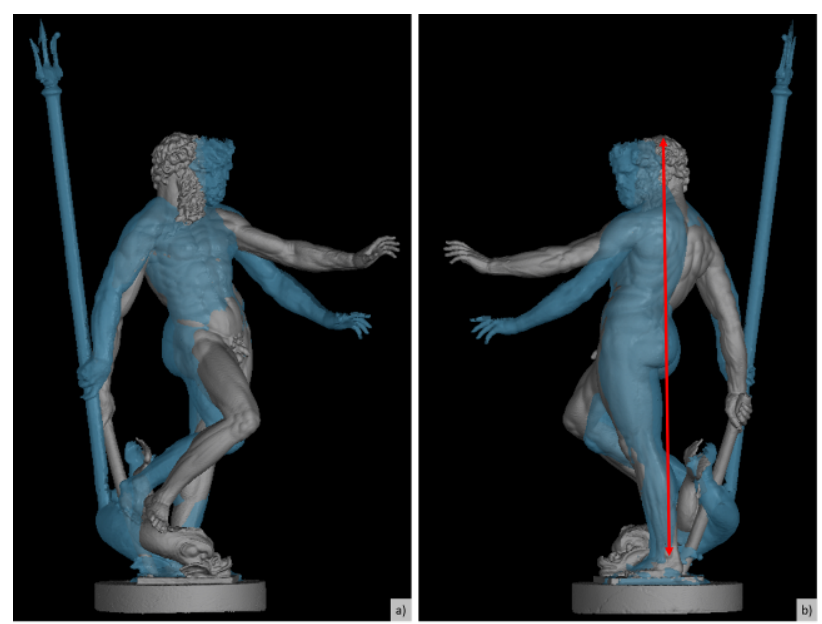

Figure 10. Two views of the comparison between the statues, after scaling of the archetype using the height, evidenced in red (the light-blue model is the big Neptune, the grey model is the archetype).

Overall it seems that the sculptor, in the realization of the final artwork, has studied the realization of some details keeping in mind its final location: the statue of the god should have been observed in its majesty from the ground and would have been placed outdoor; see for example the choice to shorten his beard, perhaps in anticipation that time and the continuous flow of water could have damaged it with encrustation and calcareous stratifications (Figure 11).

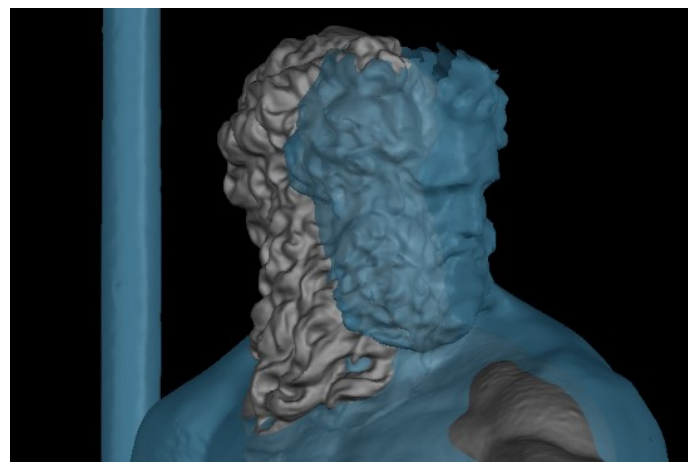

Figure 11. Detail of the head in the two statues.

\section{CONCLUSIONS}

The described application underlines the potentialities of modern geomatic techniques like 3D scanning and digital photogrammetry in the $3 \mathrm{D}$ digitisation processes of objects in the field of Cultural Heritage.

The material and geometric aspects of the objects must be evidently taken into consideration, together with other factors: the logistical aspects relating to the artworks, in particular to the context in which they are located, and the possible limitations related to the operative principle of the adopted acquisition tools.

The knowledge of some object characteristics as material and its reflectivity, dimensions, geometric complexity, etc., is fundamental for making the choice among the different available instruments or techniques and to define parameters such as sampling space, accuracy and precision.

About the survey of the archetype, the first aim was obtaining a high detailed 3D model, which could possibly also allow the replica by $3 \mathrm{D}$ printing.

The digital 3D model is suitable to metric analysis of great precision and confirms that the synthetic model allows a particularly effective exploration of the object, even higher than that which would be obtained from the direct visual consultation.

In the presented case study, some limitations presented by the two techniques appeared evident, and only their integration permitted to obtain the complete 3D model. According to this experience, it appears clear that both techniques require important manual interventions by the operator to convert the acquired data in a three-dimensional model of controlled quality.

Of great interest was the comparative study of the geometries of the big statue and its archetype, which allowed to hypothesize some considerations made by the sculptor in the realization of the final work.

Future developments of the research include attempting a nonrigid alignment between the two models and a more quantitative comparison. 


\section{ACKNOWLEDGEMENTS}

The authors would like to thank the Medieval Civic Museum of Bologna, directed by Massimo Medica, and all the partners and persons involved in the project of the restauration of the Neptune fountain, in particular the Municipality of Bologna.

Many thanks to Sara Monti, Fabrizio Girardi and Mirko Dellapasqua, who were involved in the surveying operations and data processing.

The work is partially financed by the PRIN2015 GAMHer Project.

\section{REFERENCES}

Apollonio, F. I., Basilissi, V., Callieri, M., Dellepiane, M., Gaiani M., Ponchio, F., Rizzo, F., Rubino, A. R., Scopigno, R., Sobrà, G., 2017. A 3D-centered information system for the documentation of a complex restoration intervention. J. Cult. Herit., 29, pp. 89-99, doi:10.1016/j.culher.2017.07.010.

Balletti, C., Ballarin, M., Guerra, F., 2017. 3D printing: state of the art and future perspectives. J. Cult. Herit., 26, pp. 172-182, doi:10.1016/j.culher.2017.02.010.

Bitelli, G., Balletti, C., Brumana, R., Barazzetti, L., D'Urso, M. G., Rinaudo, F., Tucci, G., 2019. The GAMHer Research Project for metric documentation of Cultural Heritage: current developments. Int. Arch. Photogramm. Remote Sens. Spatial Inf. Sci., XLII-2/W11, pp. 239-246, doi:10.5194/isprs-archivesXLII-2-W11-239-2019.

Bitelli, G., Girelli, V. A., Remondino, F., Vittuari L., 2007. The potential of 3D techniques for Cultural Heritage object documentation, Proc. SPIE 6491, Videometrics IX, 64910S. doi: $10.1117 / 12.705012$.

Bruno, F., Bruno, S., De Sensi, G., Luchi, M. L, Mancuso, S., Muzzupappa, M., 2010. From 3D reconstruction to virtual reality: a complete methodology for digital archaeological exhibition. J. Cult. Herit., 11(1), pp. 42-49.

D’Apuzzo, M. G., 2017. La collezione dei bronzi del Museo Civico Medievale di Bologna. Libro Co. Italia Ed., ISBN-13: 978-8897684268.

Francolini, C., Marchesi, G., Bitelli, G., 2018. High-resolution 3D survey and visualization of Mesopotamian artefacts bearing cuneiform inscriptions. Proc. IEEE Int. Workshop on Metrology for Archaeology and Cultural Heritage (MetroArchaeo), ISBN: 978-1-5386-5275-6, pp. 178-182.

Girelli, V. A., Tini, M. A., Dellapasqua, M., Bitelli, G., 2019. High resolution $3 \mathrm{D}$ acquisition and modelling in Cultural Heritage knowledge and restoration projects: the survey of the Fountain of Neptune in Bologna. Int. Arch. Photogramm. Remote Sens. Spatial Inf. Sci., XLII-2/W11, pp. 573-578, https://doi.org/10.5194/isprs-archives-XLII-2-W11-573-2019.

Hollinger, R. E., Edwell, J., Jr., Jacobs, H., Moran-Collins, L., Thome, C., Zastrow, J., Metallo, A., Waibel, G., Rossi, V., 2013. Tlingit-Smithsonian collaborations with 3D digitization of cultural objects. Museum Anthropology Review, 7 (1-2), pp. 201-253.

Minto, S., Remondino, F., 2014. Online access and sharing of reality-based 3D models. Sci. Res. Inf. Technol, 4, pp. 17-28.
Pieraccini, M., Guidi, G., Atzeni, C., 2001. 3D digitizing of cultural heritage. J. Cult. Herit., 2 (1), pp. 63-70, doi:10.1016/S1296-2074(01)01108-6.

Scopigno, R., Callieri, M., Cignoni, P., Corsini, M., Dellepiane, M., Ponchio, F., Ranzuglia, G., 2011. 3D Models for Cultural Heritage: Beyond Plain Visualization. IEEE Computer, vol. 44, n. 7, pp. 48-55, doi:10.1109/MC.2011.196.

Tuttle, R. J., 2015. The Neptune fountain in Bologna. Bronze, marble and water in the making of a papal city, New York. 